\title{
GCU
}

Glasgow Caledonian

University

University for the Common Good

\section{Analysis of significant factors on cable failure using the Cox proportional hazard model}

Tang, Zeyang; Zhou, Chengke; Jiang, Wei; Zhou, Wenjun ; Jing, Xiaoping; Yu, Jianhui; Alkali, Babakalli; Sheng, Bojie

Published in:

IEEE Transactions on Power Delivery

DOI:

10.1109/TPWRD.2013.2287025

Publication date:

2014

Document Version

Author accepted manuscript

Link to publication in ResearchOnline

Citation for published version (Harvard):

Tang, Z, Zhou, C, Jiang, W, Zhou, W, Jing, X, Yu, J, Alkali, B \& Sheng, B 2014, 'Analysis of significant factors on cable failure using the Cox proportional hazard model', IEEE Transactions on Power Delivery, vol. 29, no. 2, pp. 951-957. https://doi.org/10.1109/TPWRD.2013.2287025

\section{General rights}

Copyright and moral rights for the publications made accessible in the public portal are retained by the authors and/or other copyright owners and it is a condition of accessing publications that users recognise and abide by the legal requirements associated with these rights.

Take down policy

If you believe that this document breaches copyright please view our takedown policy at https://edshare.gcu.ac.uk/id/eprint/5179 for details

of how to contact us. 


\title{
Analysis of Significant Factors on Cable Failure Using Cox Proportional Hazard Model
}

\author{
Zeyang Tang, Chengke Zhou, Senior Member, IEEE, Wei Jiang, Wenjun Zhou, Senior Member, IEEE, \\ Xiaoping Jing, Jianhui Yu, Babakalli Alkali and Bojie Sheng
}

\begin{abstract}
This paper proposes the use of the Cox Proportional Hazard Model (Cox PHM), a statistical model, for the analysis of early-failure data associated with power cables. The Cox PHM analyses simultaneously a set of covariates and identifies those which have significant effects on the cable failures. In order to demonstrate the appropriateness of the model, relevant historical failure data related to Medium Voltage (MV, rated at $10 \mathrm{kV})$ distribution cables and High Voltage $(\mathrm{HV}, 110 \mathrm{kV}$ and $220 \mathrm{kV})$ transmission cables have been collected from a regional electricity company in China. Results prove that the model is more robust than the Weibull distribution in that failure data does not have to be homogeneous. Results also demonstrate that the method can single out a case of poor manufacturing quality with a particular cable joint provider by using the hypothesis test of p-value $(5 \%)$. The proposed approach can potentially help to resolve any legal dispute that may arise between a manufacturer and a network operator, in addition to providing guidance for improving future practice in cable procurement, design, installations and maintenance.
\end{abstract}

Index Terms-power cable, cable failures, Cox Proportional Hazard Model, hazard function, influencing factors, covariate.

\section{INTRODUCTION}

$\mathbf{I}^{\mathrm{N}}$ $\mathrm{N}$ China the total length of power cables rated $10 \mathrm{kV}$ and above has exceeded three hundred thousand kilometers, with most of them being commissioned for urban power transmission and distribution systems over the last 20 years [1] due to the ever-increasing rate of urbanization.

Like other power systems assets, the lifetime of cable failures obey the "bathtub curve" which can be divided into "burn-in phase" with a decreasing rate of early failures ( $0 \sim 5$ years $)$, "the useful life phase" with a low number of casual failures (5 25years) and "the wear-out phase" with an increasing rate of aging related failures (>25years) [2]. The hundreds of

Manuscript received June 27, 2013.

Zeyang Tang, Wenjun Zhou and Jianhui Yu are with the school of Electrical Engineering, Wuhan University, Wuhan, 430072, China (whu_tzy@126.com; wjzhou@whu.edu.cn; jhyu@whu.edu.cn). Wenjun Zhou is the corresponding author.

Chengke Zhou, Babakalli Alkali and Bojie Sheng are with School of Engineering and Built Environment, Glasgow Caledonian University, UK. (E-mail: c.zhou@gcu.ac.uk; Babakalli.Alkali@gcu.ac.uk;

Bojie.Sheng@gcu.ac.uk).

Xiaoping Jing and Wei Jiang are with Wuhan power supply company, Wuhan, 430054, China. cable-related failures which occur each year in the major metropolitan cities in China are mainly in the early part of the cable life cycle. Except third party or external damages which happen in a random manner, the causes for these early failures are mainly manufacturing imperfections and poor installation practices [3]-[4], despite the fact that strict procedures and technical standards are followed among cable and cable accessory manufacturers and cable installers [5]. The routine one hour DC voltage withstand test of the oversheath and the 24 hours $\mathrm{AC}$ voltage withstand test of the main insulation are also carried out after installation according to IEC-60840 [6] and IEC-62067 [7], but failures due to manufacturing imperfections and poor installation quality have still been encountered [8], as these tests can only reveal major defects that cause rapid breakdowns. Many forms of minor defects that can not be detected during the manufacturing and installation processes will gradually deteriorate and cause failures after a period of operation. These failures, often happen within the first 5 years of the cable life, are also known as early mortalities.

Existing assessment and investigation of power cable failures are based on simple calculation of the number of failures per one hundred kilometers per year or the number of failures per one hundred circuits, with considerations given occasionally to voltage ratings, cable types [9] and cable lengths. The outcome of the analysis is often inconclusive as cable failures can be due to a number of factors [10]. In addition, the existing approaches are unable to single out the most important reasons such as poor quality from a particular manufacturer or poor installation practice from a particular installation service provider with scientific underpinning.

The Weibull distribution has been used by John P. Ainscough P. E [11] to analyze the relationship between the number of failures and their time-to-failures so as to predict the number of the failures in future years. The Crow-AMSAA model has been employed by Yancy Gill [12] to establish a maintenance model of aging cable. The Poisson distribution and the Binomial distribution have been adopted in the report of CIGRE Working Group A3.06 [13] to calculate the probability of failures among high voltage equipment. All these methods analyze failures of power equipment and assume that the failures fit certain types of statistical distribution. When the failures of a particular type of equipment do not fit the required type of distribution, owing to the lack of data homogeneity, results of the analysis would then 
be compromised. In addition, none of the above methodologies give considerations to the contributing or influencing factors that are most relevant to the failures. Hence there is a strong need for a novel methodology which is capable of dealing with cable failures especially when data is inhomogeneous and associated with a number of causative mechanisms. The technical advancement would provide guidance for future cable procurement, design, installation, cable asset management and maintenance. Also it would provide scientific proof in regard to who should have been responsible for the failures when legal disputes between cable manufacturers, installation service providers and network operators occur.

The Cox Proportional Hazard Model (PHM) was firstly proposed by Cox [14] in 1972 and widely used in the medical domain to study how influencing factors affected survival time of patients [15] and in reliability analysis [16]-[17]. Compared with other statistical models as mentioned above, the greatest advantage of the Cox PHM is that it can consider the impact of more than one covariate simultaneously. This is exactly the feature required in analyzing those failure data related to early mortality among power cables as will be discussed in the next session.

\section{Cable Failure Data Collection And Analysis}

Failure and life data, to be used in this paper, are related to Medium Voltage (MV, rated at $10 \mathrm{kV}$ ) distribution cables and High Voltage (HV, $110 \mathrm{kV}$ and $220 \mathrm{kV})$ transmission cables that have been collected from a regional electricity company in China.

The HV cable data include a total of 285 cable circuits with a length of 409 kilometers and 1068 cable joints. During the period between January 2004 and December 2011, 31 failures were registered.

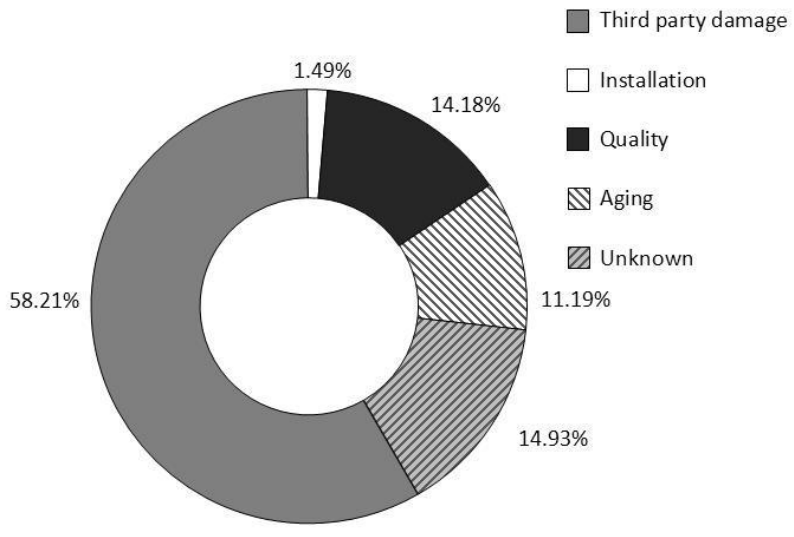

(a) Composition of MV cable failures

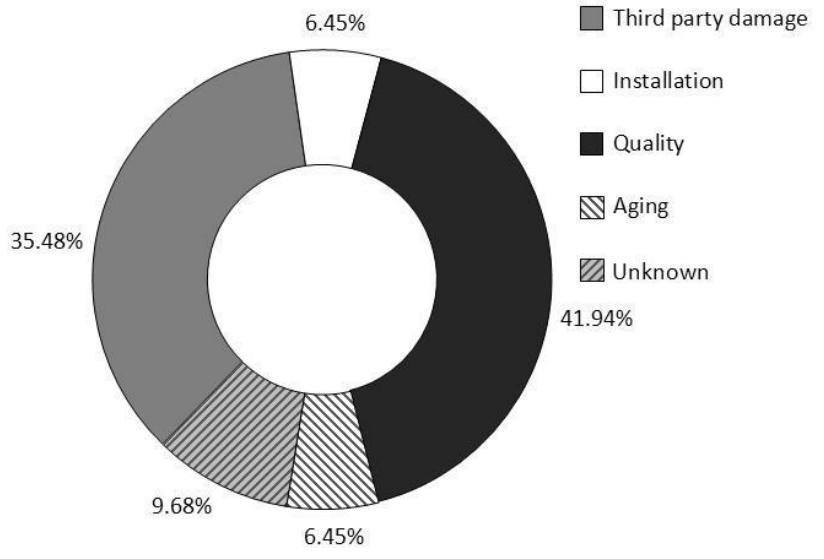

(b) Composition of HV cable failures

Fig. 1. Failure data and a breakdown of failure causes.

Among the $31 \mathrm{HV}$ failures, 18 happened to cable joints with causative mechanisms being registered as manufacturing quality issues (13), poor installation practice (2) and unknown (3), whilst third party or external damage has mainly been responsible for the remaining 13 failures associated with cable body. With the MV cables, a total of $15538 \mathrm{MV}$ cable circuits $(10 \mathrm{kV})$ with a length of 3871 kilometers, and 134 failures were observed over the period from April 2011 to March 2013. There is a lack of details with regard to the number of cable joints and the number of failures which happened to cable joints.

For each of the HV cable joints, relevant information includes the date of commissioning, the manufacturer and the installer. For MV cable circuits, available information includes the name of each of the circuits, the date of commissioning, the manufacturer, the type of installation and the circuit length. The failure data, mostly early mortalities, include date and type (joint or main cable) of each failure and the cause of each of the failures. Further information extracted from the data is presented in Fig. 1.

With the available records, cable failure mechanisms were categorized into poor practice in installation, manufacturing quality, aging, and third party damage [18-19]. However there are situations where reasons for failure were not identified and registered as "unknown". As can be seen from Fig. 1, of all the failures the percentages of unknown reasons are $14.93 \%$ and 9.68\% for MV and HV cables respectively.

\section{COX PROPORTIONAL HAZARD MOdEL}

The Cox PHM was proposed to analyze time-dependent and time-independent covariates, along with the hazard function under analysis [20]. The Cox PHM function is given in Equation (1).

$$
h(t, X)=h_{0}(t) \exp \left(\sum_{k=1}^{n_{1}} \delta_{i} \cdot X_{k}+\sum_{j=1}^{n_{2}} \gamma_{j} \cdot X_{j}\right)
$$

Where $h_{0}(t)$ is the baseline hazard function. $X_{k}$ stands for time-dependent covariates and $X_{j}$ represents 
time-independent covariates, whose regression parameters are denoted as $\delta_{i}$ and $\gamma_{j}$ respectively, $n_{1}$ and $n_{2}$ represent the number of time-dependent and time-independent covariates respectively. If the set of data under analysis obeys the Weibull distribution [21]-[22], then the baseline hazard function $h_{0}(t)$ can take the form of the Weibull model which has been a popular choice [21]-[22]. In this case the model is known as a full parameter model. However, when the focus of an analysis is on relative importance of covariates on the hazard, then $h_{0}(t)$ can be hidden. In this case the model is referred to as the half-parameter Cox PHM [23].

In this paper, only the half parameter Cox PHM model and time-independent covariates are considered. The objective of the current analysis is to identify those factors which are the most significant to cable failures. The mathematical expression function [23] is given in equation (2).

$$
h(t, X)=h_{0}(t) \exp \left(\sum_{i=1}^{n} \beta_{i} \cdot X_{i}\right)
$$

$X_{i}$ is the $i t h$ covariate that can have influence on cable failure, while $\beta_{i}$ is the regression parameter that represents the weighting of the ith covariate on the failures. When $\beta_{i}$ is positive, it means that ith covariate has a positive correlation with the failures. While $\beta_{i}$ is negative, it means that ith covariate is negatively correlated with the failures. If $\beta_{i}$ equals to 0 , it means the covariate has no correlation with the failures. SPSS, a specialized statistics software, has been employed in the current work to evaluate $\beta_{i}$ through regression analysis of the failure data. It is to be noted that although the hazard function $h_{o}(t)$ is still in Equation (2), it does not need to take a specific form and can be ignored when failure data are analyzed in SPSS.

\section{CABle FAILURE DATA ANALYSIS}

With cable failure data at hand, the procedures of carrying out the Cox PHM involve determination of covariates, setting of dummy variables, calculation of time-to-failures for each failed cases, and identifying the significance of the influencing factors using SPSS. Further explanations of the procedures are as follows.

\section{A. Determining Covariates and Evaluation of Their Weightings in the Cox PHM}

TABLE I

COVARIATES TAKEN FOR IN THE PAPER

\begin{tabular}{|l|l|l|l|}
\hline $\begin{array}{l}\text { HV cable joints } \\
\text { /covariates }\end{array}$ & Installer & $\begin{array}{l}\text { Joint } \\
\text { Manufacturer }\end{array}$ & \\
\hline Covariates/symbol & $\begin{array}{l}\text { HI } \\
\text { (HI1 HI4) }\end{array}$ & $\begin{array}{l}\text { HM } \\
\text { (HM1 HM8) }\end{array}$ & \\
\hline $\begin{array}{l}\text { MV cable circuits/ } \\
\text { covariates }\end{array}$ & $\begin{array}{l}\text { Methods of } \\
\text { installation }\end{array}$ & Manufacturer & Cable length \\
\hline Covariates/symbol & $\begin{array}{l}\text { MI } \\
\text { (MI1 MI5) }\end{array}$ & $\begin{array}{l}\text { MM } \\
\text { (MM1 MM6) }\end{array}$ & $\begin{array}{l}\text { ML } \\
(\text { ML1 ML4) }\end{array}$ \\
\hline
\end{tabular}

Failures rates related to $\mathrm{HV}$ and $\mathrm{MV}$ cables have been analysed separately. With the available data, HV cable failures and cable joint failures can be identified, which is not the case with MV cable data.

With HV failures, only the 18 joint failures need to be dealt with. Those failures due to third party damage happen in a random manner and aging failures have been ignored. Further to information provided in Fig. 1, HV joints were produced by 8 manufacturers and installed by 4 different installation companies. Information regarding the methods of installation for $\mathrm{HV}$ cables was unavailable and has not been considered. MV failure cables and cable accessories were produced by 6 manufacturers, installed in 5 different methods and cable length are divided into $0 \sim 0.5 \mathrm{~km}, 0.5 \sim 1 \mathrm{~km}, 1 \sim 1.5 \mathrm{~km}$ and $>1.5 \mathrm{~km}$. Methods of installation include "laid in cable trenches", "directly buried", "in cable conduit", "overhead support" and "unknown". The covariates of HV and MV cables are shown in Table I.

\section{B. Setting Dummy Variables}

A dummy variable is the one that takes the value 0 or 1 , indicating the absence or presence of the categorical effect of a covariate that may shift the outcome. If a covariate contains only two classes, for example, the human gender contains male and female, the dummy variable is unnecessary. In the case of, say, the covariate "length of cable" which include four classes that are $(0 \sim 0.5 \mathrm{~km}),(0.5 \sim 1 \mathrm{~km}),(1 \sim 1.5 \mathrm{~km})$ and $(>1.5 \mathrm{~km})$, dummy variables are then necessary when SPSS is used to carry out data regression [24]-[26]. Take the covariate "cable length" as an example, cable lengths of $(0 \sim 0.5 \mathrm{~km}),(0.5 \sim 1 \mathrm{~km})$, $(1 \sim 1.5 \mathrm{~km})$ and $(>1.5 \mathrm{~km})$, are recorded as 1 to 4 respectively. According to the rules of setting dummy variable, when cables of an arbitrary length group, say, a $(0 \sim 0.5 \mathrm{~km})$ or ML1, is chosen as the base for analysis, then the other three length group (ML2, ML3, ML4) are dummy variables. The codes of dummy variables can be formed for use in SPSS as given in Table II. Although the other length group can also be chosen as the base, the results will be the same. These procedures will be applied to other covariates and will not be repeated here.

TABLE II

CODES OF DUMMY VARIABLES IN SPSS WHEN ML1 IS ASSUMED AS THE BASE

\begin{tabular}{|c|c|c|c|}
\hline $\begin{array}{c}\text { Length of } \\
\text { cable/km }\end{array}$ & $\begin{array}{c}\text { (ML2)Length } \\
\text { of cable(1) }\end{array}$ & $\begin{array}{c}\text { (ML3)Length of } \\
\text { cable(2) }\end{array}$ & $\begin{array}{c}\text { (ML4)Length of } \\
\text { cable(3) }\end{array}$ \\
\hline $0 \sim 0.5$ (base) & 0 & 0 & 0 \\
\hline $0.5 \sim 1$ & 1 & 0 & 0 \\
\hline $1 \sim 1.5$ & 0 & 1 & 0 \\
\hline$>1.5$ & 0 & 0 & 1 \\
\hline
\end{tabular}

C. Calculation of Time-to-Failure and Censored Time

In this paper, the data collected are the so-called "censored data" in statistics. This means that data include both cables with and without failures till the day that data were collected. The collecting date of HV and MV cables were Dec. $1^{\text {st }} 2011$ and Feb. $27^{\text {th }} 2013$ respectively. If a cable had failed before the collecting date, then the time-to-failure of the cable can be 
calculated. With those cables still in normal operation till the collecting date, then the censored life time (between the date of commissioning and the date of data collection) of the cable was calculated. An example of the data set associated with HV cable joints after pre-processing of data and before carrying out regression is provided in Table A in Appendix at the end of the paper.

\section{Analysis of Significance of Individual Covariates}

When a particular covariate is analyzed to assess whether it has a significant effect on the failures, the Hypothesis Test [27] is applied. The Hypothesis Test includes a null hypothesis and an alternative hypothesis. The p-value [28], a statistical tool for significance testing, is adopted here in the Hypothesis test. A predetermined significance level is set as 0.05 , meaning when the $\mathrm{p}$-value is below 0.05 , the null hypothesis is refused because the chance of the null hypothesis being true is too small. However when p-value is greater than 0.05 , the null hypothesis should be accepted. Here the null hypothesis is taken as "a covariate's $\beta$ value (as shown in equation (2)) is equal to 0 " and the alternative hypothesis is taken as the "covariate's $\beta$ value is not equal to 0 ". The covariate's $\beta$ value is estimated using the Maximum Likelihood Estimation method.

\section{E. Analysis of HV Cable Joints}

Table III illustrates the results produced from the regression analysis of failure data using SPSS, where SE is the standard error of $\beta$. Wald is the value of the Wald statistics in the hypothesis test in the software package SPSS. DF is the degree of freedom. SIG is the $\mathrm{p}$ value of the hypothesis test. $\operatorname{Exp}(\beta)$ signifies the relative risk. $95 \%$ CI means $95 \%$ confidence interval. The "backward stepwise" option has been chosen in SPSS in order to delete the covariates which are not significantly correlated with failure.

TABLE III ANALYSIS RESULTS OF HV CABLE JOINT

\begin{tabular}{|c|c|c|c|c|c|c|c|c|}
\hline \multirow{2}{*}{ Covariate } & \multirow{2}{*}{$\beta$} & \multirow{2}{*}{ SE } & \multirow{2}{*}{ Wald } & \multirow{2}{*}{$\mathrm{DF}$} & \multirow{2}{*}{ SIG } & \multirow{2}{*}{$\operatorname{Exp}(\beta)$} & \multicolumn{2}{|c|}{$\begin{array}{c}95.0 \% \mathrm{CI} \text { for } \\
\operatorname{Exp}(\beta)\end{array}$} \\
\hline & & & & & & & lower & upper \\
\hline Step1 HI & & & 4.695 & 3 & 0.196 & & & \\
\hline HI1 & -2.562 & 1.307 & 3.840 & 1 & 0.050 & 0.077 & 0.006 & 1.00 \\
\hline $\mathrm{HI} 2$ & -1.704 & 1.255 & 1.845 & 1 & 0.174 & 0.182 & 0.016 & 2.127 \\
\hline HI3 & -1.354 & 1.235 & 1.202 & 1 & 0.273 & 0.258 & 0.023 & 2.906 \\
\hline HM & & & 12.795 & 7 & 0.077 & & & \\
\hline HM1 & 1.867 & 1.376 & 1.842 & 1 & 0.175 & 6.469 & 0.437 & 95.868 \\
\hline HM2 & 2.248 & 0.936 & 5.765 & 1 & 0.016 & 9.471 & 1.511 & 59.35 \\
\hline HM3 & 3.533 & 1.172 & 9.087 & 1 & 0.003 & 34.218 & 3.441 & 340.25 \\
\hline HM4 & -10.104 & 1123 & 0 & 1 & 0.993 & 0 & 0 & \\
\hline HM5 & -11.365 & 751.2 & 0 & 1 & 0.988 & 0 & 0 & \\
\hline HM6 & 2.013 & 1.358 & 2.195 & 1 & 0.138 & 7.482 & 0.522 & 107.2 \\
\hline HM7 & 0.963 & 0.910 & 1.118 & 1 & 0.290 & 2.619 & 0.440 & 15.593 \\
\hline
\end{tabular}

\begin{tabular}{cccccccccc}
\hline Step2 HM & & & 18.218 & 7 & 0.011 & & & \\
HM1 & 2.063 & 1.241 & 2.764 & 1 & 0.096 & 7.871 & 0.691 & 89.631 \\
HM2 & 2.043 & 0.818 & 6.232 & 1 & 0.013 & 7.711 & 1.551 & 38.337 \\
HM3 & 3.544 & 1.035 & 11.736 & 1 & 0.001 & 34.609 & 4.556 & 262.91 \\
HM4 & -10.651 & 1119.9 & 0 & 1 & 0.992 & 0 & 0 & \\
HM5 & -11.290 & 849.29 & 0 & 1 & 0.989 & 0 & 0 & \\
HM6 & 1.885 & 1.234 & 2.331 & 1 & 0.127 & 6.584 & 0.586 & 73.99 \\
HM7 & 0.611 & 0.837 & 0.533 & 1 & 0.465 & 1.842 & 0.357 & 9.496 \\
\hline
\end{tabular}

Two steps have been taken in SPSS. In step 1, the significance of covariates $\mathrm{HI}$ and HM were analyzed simultaneously. The SIG values of covariate HI and HM were found to be 0.196 and 0.077 respectively, both exceeded 0.05 . $\mathrm{HI}$ is ignored in the process of "backward stepwise" regression because the SIG value of HI is greater than that of HM.

In step 2, only the covariate HM was analyzed. It can be found from Table V, HM2 and HM3, their SIG values were 0.013 and 0.001 respectively, both less than 0.05 . For all the other covariates, as their SIG values were greater than 0.05 , their effects were assumed as insignificant and therefore ignored.

For $\mathrm{HM} 2$, its $\operatorname{Exp}(\beta)$ value was 7.711 meaning that the failure hazard of the cables manufactured by manufacturer 2(HM2) was 7.711 times of manufacturer 8 (HM8). Meanwhile, the $\operatorname{Exp}(\beta)$ value of HM3 is 34.609 which means that the failure hazard using the cable joints produced by the 3th manufacturer (HM3) was 34.069 times of manufacturer 8(HM8).

It can be concluded that manufacturer 2(HM2) and manufacturer 3(HM3) were significantly and positively correlated with the failures. The installation companies and other manufacturers were found to be less correlated with the cable joint failures. It is worth noting that the particular cable joint manufacturer (HM3) eventually accepted its responsibility in the failures after a long standing legal dispute. The cause of the joint failures was recognized as poor design of the stress cones.

\section{F. Analysis of MV Cable Circuits}

As shown in Table IV, the SIG values of covariate MI, MM and ML were all zeros. So no covariate should be ignored.

TABLE IV

ANALYSIS RESULTS OF MV CABLE CIRCUIT

\begin{tabular}{llllllll}
\hline Covariate & $\beta$ & SE & Wald & DF & SIG & $\operatorname{Exp}(\beta)$ & $\frac{\operatorname{Exp}(\beta)}{\text { lower } \quad \text { upper }}$ \\
\hline
\end{tabular}

\begin{tabular}{|c|c|c|c|c|c|c|c|c|}
\hline \multicolumn{3}{|l|}{ Step1 MI } & \multirow{2}{*}{$\begin{array}{c}20.155 \\
0\end{array}$} & \multirow[t]{2}{*}{4} & \multicolumn{2}{|l|}{0} & \multirow[b]{2}{*}{0.538} & \multirow[b]{2}{*}{1.879} \\
\hline MI2 & 0.006 & 0.319 & & & 0.986 & 1.006 & & \\
\hline MI3 & -2.306 & 0.532 & 18.81 & 1 & 0 & 0.100 & 0.035 & 0.283 \\
\hline MI4 & 0.824 & 0.745 & 1.225 & 1 & 0.268 & 2.280 & 0.530 & 9.816 \\
\hline MI5 & -13.187 & 821.56 & 0 & 1 & 0.987 & 0 & 0 & \\
\hline
\end{tabular}




\begin{tabular}{ccccccccc}
\hline MM & & & 68.592 & 5 & 0 & & & \\
MM2 & 0.239 & 0.280 & 0.730 & 1 & 0.393 & 1.270 & 0.734 & 2.199 \\
MM3 & 1.445 & 1.032 & 1.960 & 1 & 0.161 & 4.242 & 0.561 & 32.078 \\
MM4 & 2.227 & 0.323 & 47.476 & 1 & 0 & 9.270 & 4.920 & 17.465 \\
MM5 & -0.163 & 0.648 & 0.063 & 1 & 0.802 & 0.850 & 0.239 & 3.024 \\
MM6 & -12.065 & 176.14 & 0.005 & 1 & 0.945 & 0 & 0 & $4 \mathrm{E} 144$ \\
ML & & & 67.274 & 3 & 0 & & & \\
ML2 & 1.022 & 0.279 & 13.389 & 1 & 0 & 2.778 & 1.607 & 4.802 \\
ML3 & 2.094 & 0.279 & 56.136 & 1 & 0 & 8.118 & 4.694 & 14.039 \\
ML4 & 1.191 & 0.393 & 9.177 & 1 & 0.002 & 3.290 & 1.523 & 7.109 \\
\hline
\end{tabular}

It can be found that the SIG values of MI3, MM4, ML2, ML3 and ML4 were $0,0,0,0$ and 0.002 respectively, with all being less than 0.05 . In order to identify the most significant dummy variable from ML2, ML3 and ML4, their $\operatorname{Exp}(\beta)$ values were compared. ML3 was the most relevant with failure because the $\operatorname{Exp}(\beta)$ value of ML3 was found to be the greatest.

From the above results, it can be concluded that installation method 3(MI3), manufacturer 4(MM4) and cable length of between $1 \mathrm{~km}$ and $1.5 \mathrm{~km}$ (ML3) were significantly correlated with failures. Cables laid in conduit should be recommended when cables are installed, while Manufacturer 4(MM4) should be the last name to be recommended in future cable procurement. Higher failure rates have been found to be associated with cables with a length between $1 \mathrm{~km}$ and $1.5 \mathrm{~km}$. The reason is due to the higher number of third party damages.

\section{DISCUSSIONS}

\section{A. The Impact of Sample Size}

It was found during the investigations that the results of the PHM based analysis depend greatly on the data sample size at hand. Take the HV cable joints as an example, the total number of cable joints was 1068, while the number of failed cable joints was 18 . When the sample size of 18 was taken, i.e. only failed cable joints were considered as cable joint samples during the evaluation of covariate HM3, the significance value was 0.460 . While all the 1068 cable joints were taken as the data sample, the SIG value of covariate HM3 was 0.001 which was less than 0.05 , meaning that the covariates had effect on failures. Clearly the correct data sample should be taken if meaningful results are to be generated.

\section{B. The Effect Due to Third Party Damage on Analysis Results}

The failures are most often caused by third party damage. This category of failures encompasses a variety of failure symptoms. Some cables suffered instant failures and some failures occurred years after damage. The reason why the cases of third party damages have been taken into consideration in the paper was because they were related with installation methods and cable length. For example, a cable is more likely to be damaged by rodents if a cable is directly buried. Also the longer the cable length, the higher is the probability of third party damages. With regard to the significance of factors such as "manufacturer", ignoring failures due to third party damage may yield more useful results.

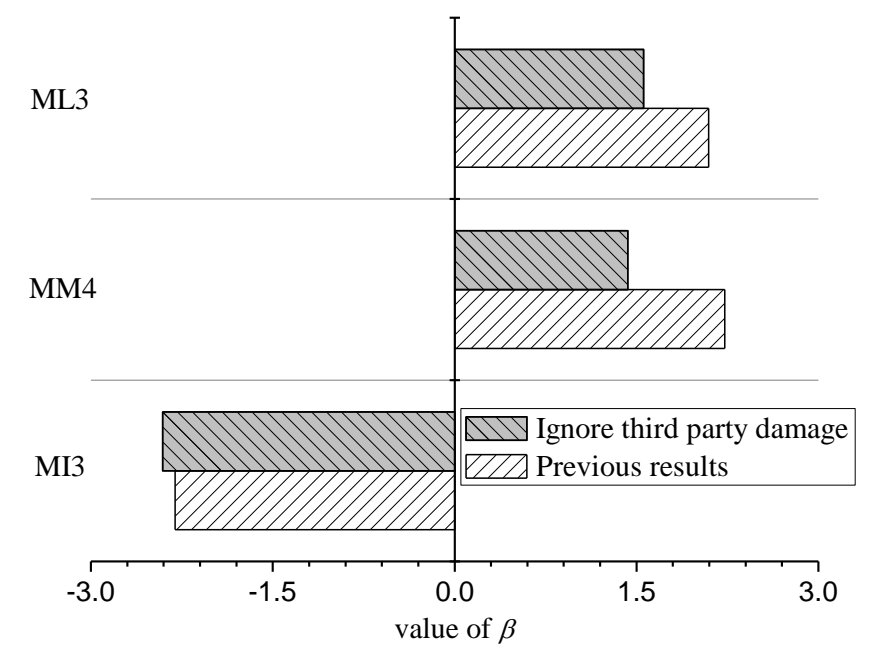

Fig. 2. Effects of significant factors with and without consideration of third party damage.

In order to assess the effect of failures due to third party damage on the analysis results, the "state" of MV cables that failed due to third party damage were changed to 0 . In other words, these cables were taken as being still in normal operation. The other settings were left unchanged. The significances of covariates MI3, MM4 and ML3 were compared with previous results. As can be seen from Fig. 2, the relative risk of covariates MI3, MM4 and ML3 decreased.

\section{CONCLUSIONS}

The paper presented a Cox PHM based approach to the analysis of a set of cable early-failure data and demonstrated that the model can help to quantify the degree of the effect of the selected covariates on cable and cable joint failures. It is capable of providing accurate decisions on the outstanding factors such as a particular manufacturer and/or an installation method which may be responsible for the failures especially when more than one factor has influence on cable failures. The model should help asset managers to deal better with early failures as the model can help to identify weak links, with scientific evidence in the processes of procurement, design and installation methods.

Compared with the Weibull distribution, the Cox PHM is more adaptive and robust because it is a semi-parameter model which does not need to know the distribution of data. The covariates used in the Cox PHM should contain the entire cable sample. Otherwise, analysis can lead to misleading results. 


\section{APPENDIX}

TABLE A

DATA INPUT TO SPSS (HV CABLE)

\begin{tabular}{|c|c|c|c|c|}
\hline No & $\begin{array}{l}\text { Time-to-failure/ } \\
\text { censored time }\end{array}$ & Installer & $\begin{array}{c}\text { Joint } \\
\text { manufacturer }\end{array}$ & $\begin{array}{l}\text { State } \\
\text { of } \\
\text { cable }\end{array}$ \\
\hline 1 & 2100 & 2 & 8 & 1 \\
\hline 2 & 620 & 3 & 3 & 1 \\
\hline 3 & 6020 & 2 & 2 & 0 \\
\hline 4 & 6086 & 3 & 1 & 0 \\
\hline 5 & 2676 & 3 & 1 & 1 \\
\hline 6 & 2676 & 2 & 2 & 1 \\
\hline 7 & -19 & 3 & 5 & 1 \\
\hline 8 & 43 & 3 & 7 & 1 \\
\hline 9 & 65 & 2 & 7 & 1 \\
\hline 10 & 4250 & 1 & 2 & 1 \\
\hline 11 & 262 & 4 & 8 & 1 \\
\hline 12 & 0 & 3 & 3 & 1 \\
\hline 13 & 730 & 3 & 7 & 0 \\
\hline 14 & 97 & 2 & 7 & 0 \\
\hline 15 & 4250 & 3 & 2 & 1 \\
\hline 16 & 168 & 2 & 4 & 0 \\
\hline 17 & 354 & 3 & 7 & 1 \\
\hline 18 & 981 & 3 & 7 & 0 \\
\hline 19 & 2629 & 3 & 7 & 1 \\
\hline 20 & 2313 & 1 & 7 & 0 \\
\hline 21 & 4532 & 2 & 7 & 0 \\
\hline 22 & 259 & 2 & 6 & 1 \\
\hline 23 & 194 & 1 & 2 & 1 \\
\hline 24 & 5 & 1 & 7 & 1 \\
\hline 25 & 125 & 2 & 7 & 0 \\
\hline 26 & 5232 & 3 & 2 & 0 \\
\hline 27 & 968 & 3 & 2 & 1 \\
\hline 28 & 2744 & 3 & 2 & 1 \\
\hline 29 & 964 & 1 & 7 & 0 \\
\hline 30 & 1148 & 2 & 7 & 0 \\
\hline 31 & 562 & 2 & 7 & 0 \\
\hline$\div \quad:$ & $\vdots \quad \vdots$ & $: \quad \vdots$ & $: \quad \vdots$ & $\vdots:$ \\
\hline 1068 & 1198 & 4 & 8 & 0 \\
\hline
\end{tabular}

(Note: the numbers in the third and fourth column of the table are taken in accordance to the rules given in Table I. In the final column of the table, the cable has failed when its "state" is given as 1 and is still in healthy or operational condition when it is 0 .)

\section{REFERENCES}

[1] Min Wang, "State grid corporation of China's yearbook 2011," China Electric Power Press, 2012: pp. 566

[2] Junhua Luo, Yuchang Qiu and Liming Yang, "Operation Fault Analysis of CLPE Power Cable above $10 \mathrm{kV}$," High voltage and engineering, Vol. 29, No. 6, pp. 14-16, 2003.

[3] Bertling L, Eriksson R, Allan R N, et al, "Survey of causes of failures based on statistics and practice for improvements of preventive maintenance plans," 14th Power Systems Computation Conference. 2002.

[4] Jorge A, Tim A, Miroslav, B, et al, "Diagnostic testing of underground cable systems," National Electric Energy Testing, Research \& Applications Center, project number, 04-211/04-212/09-166, 2010
[5] Duan Xiaoli, Tang Meiyun, Lin Feng, Ye Huisheng, "Analysis on Breakdown of Main Insulation on Middle Joint of 220 kV Power Cable," High Voltage Apparatus, vol. 45, no. 6, pp. 142-144, 2009.

[6] Standard IEC, 60840: 2011. Power Cables with Extruded Insulation and their Accessories for Rated Voltages Above, $30 \mathrm{kV}(\mathrm{Um}=36 \mathrm{kV})$ up to $150 \mathrm{kV}(\mathrm{Um}=170 \mathrm{kV})-$ Test methods and requirements.

[7] Standard IEC, 62067: 2006. Power Cables with Extruded Insulation and their Accessories for Rated Voltages Above, $150 \mathrm{kV}(\mathrm{Um}=170 \mathrm{kV})$ up to $500 \mathrm{kV}(\mathrm{Um}=550 \mathrm{kV})-$ Test methods and requirements.

[8] Wu Lihui, "Accident Analysis of Power Cable Terminal on $110 \mathrm{kV}$ Liangrong Line," Guangdong Electric Power, vol. 22, no. 5, pp. 67-69, 2009.

[9] Luo Junhua, Yang Liming, Jiang Yun and Sheng Longbao, "Outline of operation and failure and testing for power cable," Electrical equipment, vol. 5 , no. 8, pp. 4-8, 2004.

[10] X. Chen, J.J. Smit and S. Meijer, "Investigation on Insulation Reliability of $380 \mathrm{kV}$ XLPE Cable Systems," 2011 Electrical Insulation Conference, Annapolis, Maryland, pp. 434-438, June, 2011.

[11] John P. Ainscough P. E and Ian W. Forrest P. E, "Predicting medium-voltage underground-distribution cable failures," IEEE PES-ICC Fall Meeting, Scottsdale, AZ - WG C26D, pp. 1-11, Nov. 11, 2009.

[12] Yancy Gill, "Development of an electrical cable replacement simulation model to aid with the management of aging underground electrical cables," IEEE Dielectrics and Electrical insulation Systems, vol. 27, no.1, pp. 31-37, 2011.

[13] CIGRE Working Group A3.06, "Final Report of the 2004-2007 International Enquiry on Reliability of High Voltage Equipment," Part 1 Summary and General Matters, pp. 8-9, 2012.

[14] D. R. COX, "Regression Models and Life-Tables," Journal of the Royal Statistical Society. Series B (Methodological), vol. 34, no.2, pp. 187-220, 1972.

[15] Ding Li, Guo Xuan, Zhao Shan, Wang Yuefei, Kang Qinjiong and Liu Yi, "Application of Cox PHM in coagulation function analysis in patients with primary liver cancer," Journal of Xi'an Jiaotong University(Medical Sciences), vol. 31, no. 1, no. 99-103, 2012.

[16] A. Bendell, "Proportional hazards modelling in reliability assessment," Reliability Engineering, vol. 11, no. 3, pp. 175-183, 1985.

[17] Dhananjay Kumar a and Ulf Westberg, "Maintenance scheduling under age replacement policy using proportional hazards model and TTT-plotting," European Journal of Operational Research, vol. 99, no. 3, pp. 507-515, 1997

[18] Guodong Zhang. Analysis and test of cable fault [M]. Being: China Electric Power Press, 2005: 21-22.

[19] Chengke Zhou, Xiaoping Jing, Zeyang Tang, Wei Jiang, Babakalli Alkali, Wenjun Zhou, and Jianhui Yu, "Statistical approaches for analysis of failure data in power cables," CIGRE, Paris France, D1-314, pp. 1-9, 2012.

[20] Abbas Barabadi, Javad Barabady and Tore Markeset, "Maintainability analysis considering time-dependent and time-independent covariates," Reliability engineering and system safety, vol. 96, no. 1, pp. 210-217, 2011

[21] Ireneusz J. Jozwiak. An introduction to the studies of reliability of systems using the Weibull proportional hazards model[J]. Microelectronics Reliability, 1997, 37(6): 915-918.

[22] A. K. s. Jardine, P. M. Anderson, D. s. Mann. Application of the Weibull proportional hazards model to aircraft and marine engine failure data[J]. Quality and Reliability Engineering International, 1987, 3(2): 77-82.

[23] Dhananjay Kumar and Ulf Westberg, "Proportional hazards modeling of time-dependent covariates using linear regression: a case study," IEEE Transactions on reliability, vol. 45, no. 3, pp. 386-392, 1996.

[24] Daniel B. Suitsa, "Use of dummy variables in regression equations," Journal of the American statistical association, vol. 52, no. 280, pp. 548-551, 1957.

[25] Imre Karafiath, Using dummy variables in the event methodology," The financial review, 1988, 23(3): 351-357.

[26] A. L. F. Leitao and D. W. Newton, "Proportional hazards modelling of aircraft cargo door complaints," Quality and Reliability Engineering International, vol. 5, no. 3, pp. 229-238, 1989

[27] Steven N. Goodman, "P Values, hypothesis Tests, and likelihood: implications for epidemiology of a neglected historical debate," Medicine American Journal of Epidemiology, vol. 137, no. 5, pp. 485-496, 1993. 
[28] Goodman, SN (1999). "Toward Evidence-Based Medical Statistics. 1: The P Value Fallacy.". Annals of Internal Medicine 130: 995-1004.

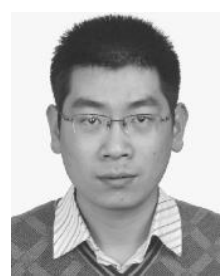

Zeyang Tang was born in Jingzhou, Hubei province, China, in 1987. He received the B.Sc. degree from the School of Electrical Engineering, Tianjin University, China in 2009.

He is currently pursuing the Ph.D. degree in School of Electrical Engineering, Wuhan University, China. His research is mainly focused on cable failure data analysis.

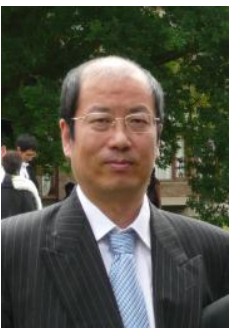

Chengke Zhou (SM'13) received the B.Sc. and M.Sc. degrees in 1983 and 1986, respectively, from the Huazhong University of Science and Technology, Wuhan, China. He received the Ph.D. degree in 1994 from the University of Manchester, Manchester, U.K. He joined the School of Engineering and Computing, Glasgow Caledonian University (GCU), Glasgow, U.K., in 1994 and became a Postdoctoral Research Fellow, Lecturer, and Senior Lecturer until August 2006 when he joined Heriot-Watt University as a Reader. In June 2007, he returned to GCU as a Professor. He has more than 20 years research experience in power systems and partial discharge-based HV plant condition monitoring and has acted as a Consultant to EDF Energy, Scottish Power plc, and British Energy. He has so far published well over 100 papers. He is also a Fellow of IET and a Chartered engineer.

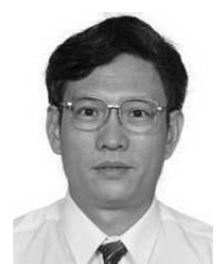

Wenjun Zhou was born in China on 1 July 1959. He received the $\mathrm{Ph}$.D. degree in 1990 from Wuhan University of Hydraulic \& Electrical Engineering. Currently, he is a professor at the School of Electrical Engineering of Wuhan University, China. He is a member of the High Voltage Committee of the Chinese Society of Electrical Engineering (CSEE), the Electro-technical Test and Measurement Committee of the China Electro-technical Society (CES), and the China Lightning Protection Standard Committee. He is also the vice director of the Hubei High Voltage Committee. His research interests include lightning protection and the diagnostic techniques for outdoor electrical insulations. 